\title{
Paraplegia
}

\section{Spinal Cord Injury Surveillance in the United States: An Overview}

\author{
C. L. Harrison, MS, M. Dijkers, PhD
}

Research Department, Rehabilitation Institute of Michigan, 261 Mack Blvd, Detroit, Michigan 48201, USA.

\begin{abstract}
Summary
In the United States, injuries are the leading cause of premature lost years of life, surpassing cancer and heart disease combined. Public health surveillance of injuries such as spinal cord injury (SCI) has recently begun to evolve, following decades of experience with similar methods for infectious and chronic disease conditions. In 1985, the Federal Government's Centers for Disease Control began to promote the development of surveillance systems for sentinel injuries at both the state and national level. Many states have developed, or are in the process of developing, statewide registries for SCI. The rationale behind the establishment of these registries is 4-fold: (1) to identify SCI persons in order to facilitate and coordinate provision of health and other services; (2) to gather accurate data for injury prevention efforts and planning for needed services; (3) to evaluate services provided, and (4) to document outcome and cost-effectiveness of care systems. The purpose, content and scope of these registries are reviewed in detail. Key words: Spinal cord injuries; Registries; Epidemiology; Prevention
\end{abstract}

In the United States, injuries account for more death and disability in the 1 to 44year-age group than all communicable diseases and other conditions combined.

In 1985, a landmark report by the National Academy of Sciences' Committee on Trauma Research, 'Injury in America', documented the need for more adequate data on the epidemiology of all types of injuries. The Committee reported that despite the magnitude of the injury problem, data on the incidence and prevalence of most injuries and their outcome is severely lacking. Most evident is the lack of information on the outcome of all types of nonfatal injuries (Committee on Trauma Research, 1985).

As a result of its inquiry, the Committee recommended the establishment of 
injury surveillance systems, at both state and national levels, to gather and integrate information from a variety of sources on which to base the planning and evaluation of injury control efforts.

\section{The public health impact of spinal cord injury}

Traumatic spinal cord injury (SCI) has been described as the most catastrophic of all disabling conditions. The father of modern SCI management, Sir Ludwig Guttmann, wrote that 'of the many forms of disability which can beset mankind, a severe injury or disease of the spinal cord undoubtedly constitutes one of the most devasting calamities in human life' (Guttmann, 1976).

Kraus (1985) reviewed the recent international literature describing the epidemiologic features of SCI and stated that although studies differed somewhat in methodology (i.e., case ascertainment and scope definitions) they could be used to provide a general picture of the incidence and prevalence of SCI. Many of these studies differ from the public health surveillance study design in that they are based on survey data using population samples, or are descriptions of hospitalised case series which often lack the rigour of epidemiologic study design.

According to the studies reviewed by Kraus, the incidence rate for SCI in the United States can be estimated to be between 28 and 50 per million population per year. This represents between 6700 and 12000 new traumatic SCI occurring each year. The United States rates were generally higher than those reported from other developed countries (i.e., Australia, Canada, Norway, France).

Kraus also reported that data on the number of individuals disabled by SCI is severely lacking. Estimates are limited by many confounding factors but the prevalence rate has been reported in two studies to be approximately 900 per million population per year.

The Department of Health and Human Services has recently distributed a draft of the 'Year 2000 health objectives for the nation'. Several areas specific to injuries are addressed, including the reduction of non-fatal SCI to no more than 24 per million population per year (US Department of Health and Human Services, 1989).

SCI have a particularly severe impact on the public's health because of the high costs associated with treatment, the young age of most victims, and the permanence of the disability. The cost of patient care and services, equipment, lost wages, etc. is staggering. The cost of SCI in terms of loss of quality of life cannot be estimated. Additionally, many spinal injuries-such as those caused by motor vehicle crashes and firearms - may be preventable (National Committee for Injury Prevention and Control, 1989).

\section{Spinal cord injury surveillance}

\section{National database of the Model Spinal Cord Injury Systems}

In 1973, the United States Department of Education, National Institute on Disability and Rehabilitation Research began to provide funding to establish Regional Model Spinal Cord Injury Systems. These Model Systems (currently there are 13 in existence) emphasise the state-of-the-art approach in all aspects of 
the treatment and management of traumatic SCI, from evacuation at the injury site through rehabilitation and life-time follow-up. All Regional Model Systems are obligated to submit data to a central database at the National Spinal Cord Injury Statistical Center in Birmingham, Alabama.

Information is collected on $\mathbf{4 4}$ detailed variables for the time period from initial hospitalisation to definitive discharge from the Spinal Cord Injury Care System, and 31 detailed variables for each yearly follow-up examination thereafter. This information is collected on every SCI patient treated in one of the Regional Model Systems.

Specific criteria have been established for inclusion in the Model Systems' Database. The current criteria are:

-Patients must reside in, and must have been injured within the SCI Care System's designated catchment area.

-Patient must have been admitted to the SCI Care System within 60 days after injury.

-Patients must sign informed consent to participate.

-Patients must have a clinically discernible degree of spinal cord neurologic impairment on admission to the SCI Care System.

-Patients are expected to receive all care components through the SCI Care System and be discharged from the System as: (1) normal neurologically; (2) expired, or (3) having completed rehabilitation.

Currently this database contains over 12000 cases and up to 16 years of followup information on some of the first cases entered. The 'national capture' rate for the database (the ratio of patients entered into the national database to the estimated number of SCI occurring in the United States in a given year) has been estimated to be approximately $14 \%$ (Stover and Fine, 1986).

The information in the national database has been used to analyse epidemiologic features of the SCI disabled population, evaluate treatment outcomes, analyse costs, and foster local and collaborative research projects involving all the Model Systems (Stover and Fine, 1986). However, considering the limitations set forth by the inclusion criteria, caution should be taken in utilising this unrepresentative population sample for epidemiologic analysis. The database includes only cases treated in the Model Systems, limited by a designated catchment area. Due to the fact that admission to a System is not mandatory, less than $100 \%$ of the cases in the catchment area are treated in each system. The database also excludes deaths prior to hospitalisation and unusual discharges (e.g., Against Medical Advice), etc. Additionally, the criteria for inclusion (i.e., catchment area, time between injury and admission), the information collected, and the number and location of model systems have changed significantly over the period of years the database has been in existence.

\section{Spinal cord injury surveillance at the state level}

\section{Spinal cord injury as a Reportable Condition}

In 1987, the Council of State and Territorial Epidemiologists (CSTE) passed a 
resolution recommending that acute traumatic SCI be the first injury condition to become reportable to the National Notifiable Disease System. This wellestablished system requires all physicians and health care facilities to report all cases of selected diseases (e.g., infectious hepatitis, tuberculosis) to their state health department, which in turn consolidates and forwards the data to the CDC. The Council suggested that the addition of SCI as a notifiable condition would serve as a prototype for the future inclusion of other serious injuries in this system (National Committee for Injury Prevention and Control, 1989).

\section{State spinal cord injury registries}

Epidemiologists often make a distinction between a surveillance system and a registry. A 'surveillance system', generally has a public health emphasis containing only descriptive information used to assess the magnitude of a disease or injury problem (i.e., incidence, prevalence) and is geared toward prevention. A 'registry' is typically a clinical or service oriented system used to identify patients eligible for services, evaluate treatment methods, and monitor patient outcome.

In the following discussion of statewide systems for collection of data on SCI, it will become apparent that depending on the purpose of the system, a mixture of these two entities exists. Nonetheless, for the purposes of this paper, the term registries will be used.

In the last decade there has been considerable development of SCI registries at the state level. Currently 15 states have established SCI registries, 12 of which have mandatory reporting (see Table I). The first state began data collection in 1970,

Table I Information on spinal cord injury registries

\begin{tabular}{lcc}
\hline State & $\begin{array}{c}\text { Legislative } \\
\text { reporting } \\
\text { mandate }\end{array}$ & $\begin{array}{c}\text { Year registry } \\
\text { began SCI data } \\
\text { collection }\end{array}$ \\
\hdashline Alabama & No & 1970 \\
Arkansas & Yes & 1977 \\
Colorado & Yes & 1985 \\
Florida $\star$ & Yes & 1980 \\
Georgia & Yes & 1981 \\
Illinois & Yes & 1989 \\
Iowa & Yes & 1988 \\
Louisiana & Yes & 1985 \\
Maryland & Yes & 1984 \\
Michigan & Yes & 1989 \\
Missouri & Yes & 1987 \\
New Jersey & No & 1985 \\
North Dakota & No & 1987 \\
Oklahoma & Yes & 1987 \\
Texas & Yes & 1989 \\
Utah & Yes & 1988 \\
Virginia $\star \star$ & Yes & 1978 \\
West Virginia & Yes & 1986 \\
\hline
\end{tabular}

^Some Wyoming hospitals participate in the Colorado registry.

$\star \star$ Florida and Virginia have SCI registries which function separately from their trauma registry which also includes SCI. 
although most registry development at the state level has been within the last 5 years. Additional states are in the process of developing similar systems or have introduced proposals into their legislative process (e.g., California, Michigan, North Carolina, New York, Illinois, Texas).

Systematic review and comparison of the existing registries shows considerable differences in terms of purpose, content, and methods. Some states have registries which require reporting of other conditions in addition to SCI (e.g., traumatic brain injury, stroke, non-traumatic neurologic conditions, and other types of trauma). In this report, we will focus strictly on the collecting and reporting of SCI information.

Most SCI registries are administered by state departments of either health, human services, or labour and employment. Specific divisions within the state departments in which registries function include vocational rehabilitation services, emergency services, epidemiology services, and public health services.

Some states have registries that are associated with or funded by other organisations such as the Centers for Disease Control, the National Institute on Disability and Rehabilitation Research.

\section{Purpose of Registries}

The purpose for which statewide SCI registries are established varies by state. The following are the most frequently stated objectives of these registries; many fulfill multiple purposes:

(1) To identify SCI persons in order to facilitate and coordinate provision of various rehabilitation and other support services.

(2) To gather data for (a) injury prevention and control and/or (b) planning for needed services.

(3) To evaluate services provided to SCI persons.

(4) To document outcome and cost-effectiveness of care systems.

The function of a particular registry is controlled by who is administrating the registry and the agency's primary mission. Registries located in state vocational rehabilitation agencies focus primarily on facilitation and coordination of rehabilitation services available to the injured person (e.g., Georgia, Virginia, USA). Missouri's registry is administrated through its emergency medical services division, and one of its purposes is to gather information to evaluate emergency services provided to the SCI. The Oklahoma registry is administered through its people with an injury epidemiology division and focuses on prevention.

\section{Definition of spinal cord injury}

States vary in their definition of what constitutes a reportable case. The definition used is dependent on the range of cases the administrating agency is interested in identifying or serving.

The Centers for Disease Control have developed the following definition of SCI as a guideline for use in surveillance at the state level: 
'A person who suffers an acute, traumatic lesion of neural elements in the spinal canal, resulting in any degree of sensory deficit, motor deficit, or bladder/bowel dysfunction. The deficit or dysfunction can be temporary or permanent. (Intervertebral disc disease should not be included)'.

This definition is very similar to that used by most States and some have adopted the exact CDC defintion for the surveillance of traumatic SCI.

\section{Casefinding criteria}

Some States (e.g. Florida, Louisiana, Georgia, Iowa, Virginia, Missouri) utilise a section of the ninth revision of the International Classification of Diseases (ICD-9$\mathrm{CM}$ ), the so-called nature of injury codes ( $\mathrm{N}$-codes), to aid their reporting sources in identifying potential cases for inclusion. The majority of health care facilities use the ICD-9-CM classification scheme to code all patient diagnoses. Building upon this basis is logical and contributes to the efficiency of data collection.

The Centers for Disease Control have proposed that the following ICD-9-CM $\mathrm{N}$-codes be used for identifying potential cases for inclusion in a SCI registry:

342-hemiplegia, nos (not otherwise specified)

344 other paralytic syndromes (includes paraplegia and quadriplegia, nos)

805-fracture of vertebral column without mention of SCI

806 - fracture of vertebral column with SCI

839-other, multiple, and ill-defined dislocations

952-SCI without evidence of spinal bone injury

953-injury to nerve roots and spinal plexus

When all of these codes are used for casefinding, they tend to identify a larger number of cases than actually would be included in the registry. The most specific codes, identifying the majority of new acute SCI cases, are 806 and 952. However, if these are the only codes used, some cases that may be misclassified but fit the registry's definition for inclusion would be missed.

For example, a diagnosis of paraplegia with no other information available may be coded as 344 . This code may or may not be indicative of a traumatic injury and fit criteria for inclusion depending on what caused the paraplegia (e.g., SCI, multiple sclerosis). Therefore, these codes can be used to identify potential cases, but the medical records themselves may need to be reviewed to determine whether they fit the definition for reporting.

The actual codes used for casefinding identified by each state vary depending on the scope of the registry, although most states have accepted the codes recommended by the CDC.

\section{Case inclusion criteria}

Case inclusion criteria determine the scope of the injury problem to be addressed and specify particular cases to be included in or excluded from a registry. In order to obtain a complete picture of an injury problem, all cases should be included. However, this is not always practical, properly funded, or necessary in order to 
fulfill the purposes of some types of registries. The inclusion criteria must be considered when analysing registry data, as they indicate the limitations of the information available.

The existing statewide registries vary considerably in terms of their inclusion criteria, based on differences in purpose, scope and legislation. The following are issues which have been addressed by the various states in determining the inclusion criteria for their registries:

Severity of injury. The potential range of the severity of the injuries reported is dependent on who is required to report. For example, if inclusion requires at least a 1-day admission to a hospital, those cases that only report to a clinic, doctors' office, or only require emergency room services would not be included, nor would those victims who die on the scene or in transport to a hospital.

In the case of SCI, only in very rare instances would a person with any symptoms of paralysis not be admitted to a hospital. Therefore, to require reporting from clinics, emergency rooms and doctors' offices does not contribute a significant number of cases, although it may give some indication of the incidence of very mild injury.

It is, however, very important to consider inclusion of those cases of SCI that do not reach a hospital prior to death or who are dead on arrival at the hospital, as these represent the most severe of injuries. These cases, however, will have to be accessed through a system other than the hospitals (i.e., Coroner/Medical Examiner records, autopsy reports, state death certificate files, etc.) and these types of data also have many limitations.

Catchment area. States vary in their reporting requirements in terms of three catchment area criteria: residence in state, injury in state, and treatment in state. Some include only state residents, others include all those injured and/or treated in the state regardless of residency.

There are a few points to consider with respect to these criteria. If all state residents with SCI are to be included, one must consider the difficulty in determining the number of SCI's occurring to residents outside the state (i.e., while travelling), unless they return to their home state for treatment.

Reporting all those who are injured in the state, regardless of residency, makes it very difficult to determine rates because the population at risk cannot be accurately determined, especially in states with an active tourist industry. Finally, in order to get a true picture of the impact of SCI on the health care system in a state, one must consider including all cases treated in the state regardless of place of injury or residency status. These are not minor problems due to the high mobility of the US population. Millions cross state lines every day for purposes of work, shopping or leisure. The number included in the registry depends on the criteria set, and these must be taken into consideration during analysis of the data.

Time since onset. Depending on the severity of injury, the associated injuries, and the organisation of treatment systems, a person with SCI may require initial post-injury treatment and rehabilitation in more than one facility. Patients may also require readmission to a hospital for complications after initial rehabilitation has been completed. If every hospital is obligated to report all cases of SCI, duplicate reporting of cases may occur which can skew incidence rates.

Two possible methods can be used to manage this problem. Computer casematching can be used to check for duplicate reporting so cases are counted only 
once for each injury occurrence. Another method is to specify 'time since injury' criteria for reporting. The following are a few examples of how these criteria can be defined:

- report only cases that represent 'new', 'acute' injuries

- report only hospitalisations from injury to completion of initial acute care and rehabilitation post-injury

- require only the first hospital admission/contact after injury is obligated to report.

If a registry is set up purely for identification of new cases, reporting by the first hospital the patient is admitted to following injury is all that may be necessary. However, if the administrating agency is also interested in tracking treatment referral patterns within the state, or in treatment outcomes, reporting by all hospitals treating the case is necessary.

\section{Reporting requirements}

Many states with a legislative mandate for reporting specify in the legislation who is required to report. Some further clarify these requirements in the regulations which are promulgated to implement the registry. Hospitals are the most common source for SCI reporting. Some states (e.g., Arkansas, Georgia and North Dakota) require broader reporting, for example from all public/private health and social agencies, physicians, emergency medical services staff, and chief medical examiners.

In terms of hospital reporting, there is considerable variety as to who within a hospital is responsible for submitting reports. Some states (Florida and Missouri) specify a particular department within the hospital (e.g., emergency, medical records), others (e.g., West Virginia and New Jersey, Colorado and Georgia) require hospitals to designate a contact person responsible for reporting.

All states with mandatory reporting require cases to be reported within a particular period of time after admission to the reporting facility, the length of which depends on the purpose of the registry. Those states which need immediate notification of cases in order to provide information to patients regarding services available to them, require reporting from within 5 to 14 days after admission to the reporting facility (e.g. Arkansas, Florida, Georgia, Iowa, Maryland, Colorado, North Dakota, Virginia and West Virginia). Reporting can be in the form of a tollfree call-in system or a standardised mail-in postcard or short form. Registries that collect more comprehensive information on various aspects of hospital care (e.g., in order to evaluate the medical care system) usually require reporting anywhere from 30 to 90 days after the patient is discharged from the reporting facility.

Some states (e.g., Florida, Colorado, Oklahoma, West Virginia, Georgia and Iowa) use a two-step reporting system. They require an initial report, with some very basic information, within a few days after case identification. The second part of the reporting requires the collection of more detailed information on each case (gathered by rehabilitation counsellors, hospital staff, and/or registry staff) which must be submitted after the patient is discharged from the hospital. 
Another method used by some states is to utilise computerised data linkage capabilities to match cases with other statewide databases (e.g., hospital discharge database, trauma registry) to provide quality control and add more comprehensive information to the registry.

The advantage of these two-part systems is that information is readily available to provide prompt service interventions or the immediate identification of clusters

Table II Information collected by SCI registries

(See note at end of table for meaning of codes used for individual states)

\begin{tabular}{|c|c|c|c|c|c|c|c|c|c|c|c|c|c|c|c|c|}
\hline Patient & UT & FL & WV & $\mathrm{CO}$ & VA & GA & $\mathrm{AL}$ & IA & LA & $\mathrm{MD}$ & MO & $\mathrm{AR}$ & $\mathrm{NJ}$ & ND & OK & $\mathrm{CDC}$ \\
\hline Name & $\mathrm{X}$ & $\mathrm{XT}$ & XR & $\mathrm{X}$ & $\mathrm{XH}$ & $\mathrm{XV}$ & $\mathrm{X}$ & $\mathrm{X}$ & $\mathrm{X}$ & $\mathrm{X}$ & $\mathrm{X}$ & $\mathrm{X}$ & $\mathrm{X}$ & $\mathrm{T}$ & PI & \\
\hline Address, City, State, Zip & $\mathrm{X}$ & $\mathrm{XT}$ & $\mathrm{XR}$ & $\mathrm{X}$ & $\mathrm{XH}$ & $\mathrm{X}$ & $\mathrm{X}$ & $\mathrm{X}$ & $\mathrm{X}$ & $\mathrm{X}$ & $\mathrm{X}$ & $\mathrm{X}$ & $\mathrm{X}$ & $\mathrm{T}$ & $P$ & \\
\hline County of residence & $\mathrm{X}$ & XT & & $\mathrm{X}$ & XHT & & $\mathrm{X}$ & & $\mathrm{X}$ & $\mathrm{X}$ & $\mathrm{X}$ & $\mathrm{X}$ & & $\mathrm{T}$ & $P$ & $\mathrm{X}$ \\
\hline Phone number & $\mathrm{X}$ & $\mathrm{X}$ & $\mathrm{XR}$ & $\mathrm{X}$ & $\mathrm{XH}$ & $\mathrm{X}$ & & & $\mathrm{X}$ & & & $\mathrm{X}$ & $\mathrm{X}$ & & $\mathbf{P}$ & \\
\hline Name parent/guardian & & & & & $\mathrm{X}$ & & & $\mathrm{X}$ & $\mathrm{X}$ & $\mathrm{X}$ & & & & & & \\
\hline Birthdate & $\mathrm{X}$ & XT & $\mathrm{XR}$ & $\mathrm{X}$ & XHT & $\mathrm{X}$ & & $\mathrm{X}$ & $\mathrm{X}$ & $\mathrm{X}$ & $\mathrm{X}$ & $\mathrm{X}$ & $\mathrm{X}$ & & PI & \\
\hline Age & $\mathrm{X}$ & XT & & $\mathrm{X}$ & $\mathrm{XHT}$ & $\mathrm{X}$ & $\mathrm{X}$ & $\mathrm{X}$ & $\mathrm{X}$ & $\mathrm{X}$ & & $\mathrm{X}$ & $\mathrm{X}$ & $\mathrm{T}$ & PI & $\mathrm{X}$ \\
\hline Social security number & $\mathrm{X}$ & $\mathrm{X}$ & $\mathrm{XR}$ & $\mathrm{X}$ & $\mathrm{XH}$ & $\mathrm{X}$ & $\mathrm{X}$ & $\mathrm{X}$ & & & $\mathrm{X}$ & $\mathrm{X}$ & & & & \\
\hline Sex & $\mathbf{X}$ & $\mathrm{XT}$ & $\mathrm{XR}$ & $\mathrm{X}$ & XHT & $\mathrm{X}$ & $\mathrm{X}$ & $\mathrm{X}$ & $\mathrm{X}$ & $\mathrm{X}$ & $\mathrm{X}$ & $\mathrm{X}$ & $\mathrm{X}$ & $\mathrm{T}$ & PI & $\mathrm{X}$ \\
\hline Race & $\mathrm{X}$ & $\mathrm{T}$ & $\mathbf{R}$ & $\mathrm{X}$ & HT & $\mathrm{X}$ & $\mathrm{X}$ & & $\mathrm{X}$ & $\mathrm{X}$ & $\mathrm{X}$ & $\mathrm{X}$ & $\mathrm{X}$ & $\mathrm{T}$ & PI & $\mathrm{X}$ \\
\hline Marital status & $\mathrm{X}$ & $\mathrm{X}$ & $\mathbf{R}$ & $\mathrm{X}$ & $\mathrm{H}$ & $\mathrm{X}$ & & & & $\mathrm{X}$ & & & & $\mathrm{T}$ & RI & \\
\hline Education & $\mathbf{X}$ & & $\mathbf{R}$ & $\mathrm{X}$ & $\mathrm{H}$ & $\mathrm{V}$ & & & & & & $\mathrm{X}$ & & & I & \\
\hline Occupation & $\mathrm{X}$ & & $\mathbf{R}$ & $\mathrm{X}$ & $\mathrm{H}$ & V & & & & & & $\mathrm{X}$ & $\mathrm{X}$ & $\mathrm{T}$ & RI & \\
\hline Employer & & & & & & & & & & & & & $\mathrm{X}$ & & & \\
\hline Number of hours working & & & & & $\mathrm{H}$ & & & & & & & & & & & \\
\hline Income & & & & & $\mathrm{H}$ & & & & & & & $\mathrm{X}$ & & & I & \\
\hline Number of dependents & & $\mathrm{X}$ & & & & $\mathrm{X}$ & & & & & & & & & & \\
\hline Name of supportive contact & & $\mathrm{X}$ & $\mathrm{XR}$ & & $\mathrm{X}$ & & & & & & & & & & & \\
\hline Address supportive contact & & $\mathrm{X}$ & $\mathrm{XR}$ & & $\mathrm{X}$ & & & & & & & & & & & \\
\hline Phone number supportive contact & & $\mathrm{X}$ & $\mathrm{XR}$ & $\mathrm{X}$ & $\mathrm{X}$ & & & & & & & & & & & \\
\hline Veteran status & & & & $\mathrm{X}$ & $\mathrm{X}$ & & & & & & & $\mathrm{X}$ & & & & \\
\hline Type of insurance/payment source & & & $\mathbf{R}$ & $\mathrm{X}$ & & V & & & & & $\mathrm{X}$ & $\mathrm{X}$ & & & & $\mathrm{X}$ \\
\hline Injury circumstances & UT & FL & WV & $\mathrm{CO}$ & VA & GA & $\mathrm{AL}$ & IA & LA & MD & MO & $\mathrm{AR}$ & $\mathrm{NJ}$ & ND & OK & $\mathrm{CDC}$ \\
\hline Date onset/injury & $\mathrm{X}$ & $\mathrm{XT}$ & $\mathrm{XR}$ & $\mathrm{X}$ & XHT & $\mathrm{X}$ & $\mathrm{X}$ & & $\mathrm{X}$ & $\mathrm{X}$ & $\mathrm{X}$ & $\mathrm{X}$ & $\mathrm{X}$ & $\mathrm{T}$ & PI & $\mathrm{X}$ \\
\hline Time of injury & $\mathrm{X}$ & $\mathrm{T}$ & $\mathrm{XR}$ & $\mathrm{X}$ & & & & & $\mathrm{X}$ & & $\mathrm{X}$ & $\mathrm{X}$ & & $\mathrm{T}$ & I & $\mathrm{X}$ \\
\hline Location of injury & $\mathrm{X}$ & & $\mathbf{R}$ & $\mathrm{X}$ & & & & & $\mathrm{X}$ & & & & & $\mathrm{T}$ & I & \\
\hline County of injury & $\mathrm{X}$ & $\mathrm{XT}$ & & $\mathrm{X}$ & $\mathrm{T}$ & $\mathrm{X}$ & $\mathrm{X}$ & & $\mathrm{X}$ & $\mathrm{X}$ & $\mathrm{X}$ & $\mathrm{X}$ & & & I & $\mathrm{X}$ \\
\hline State of injury & $\mathrm{X}$ & & & $\mathrm{X}$ & & & $\mathrm{X}$ & & $\mathrm{X}$ & & $\mathrm{X}$ & $\mathrm{X}$ & $\mathrm{X}$ & & I & $\mathrm{X}$ \\
\hline Cause of injury & $\mathrm{X}$ & $\mathrm{XT}$ & $\mathrm{XR}$ & $\mathrm{X}$ & XHT & $\mathrm{XV}$ & $\mathrm{X}$ & $\mathrm{X}$ & $\mathrm{X}$ & $\mathrm{X}$ & & $\mathrm{X}$ & $\mathrm{X}$ & $\mathrm{T}$ & PI & $\mathrm{X}$ \\
\hline E-code (external cause) & $\mathrm{X}$ & $\mathrm{T}$ & & $\mathrm{X}$ & $\mathrm{T}$ & $\mathrm{X}$ & & & $\mathrm{X}$ & & $\mathrm{X}$ & $\mathrm{X}$ & & $\mathrm{T}$ & & $\mathrm{X}$ \\
\hline Description of injury event & & $\mathrm{T}$ & & $\mathrm{X}$ & & $\mathrm{X}$ & & & $\mathrm{X}$ & & $\mathrm{X}$ & $\mathrm{X}$ & & $\mathrm{T}$ & PI & \\
\hline Alcohol/drug involvement & $\mathrm{X}$ & $\mathrm{X}$ & $\mathrm{XR}$ & $\mathrm{X}$ & $\mathbf{H}$ & $\mathrm{XV}$ & & & $\mathrm{X}$ & & $\mathrm{X}$ & $\mathrm{X}$ & & $\mathrm{T}$ & $\mathrm{RI}$ & $\mathrm{X}$ \\
\hline Impaired mental status at injury & & & & $\mathrm{X}$ & & & & & & & & & & & $\mathrm{RI}$ & \\
\hline Work related injury & $\mathrm{X}$ & $\mathrm{TX}$ & & $\mathrm{X}$ & & $\mathrm{XV}$ & & & $\mathrm{X}$ & & $\mathrm{X}$ & $\mathrm{X}$ & & $\mathrm{T}$ & I & $\mathrm{X}$ \\
\hline If work related, & & & & & & & & & & & & & & & & \\
\hline Type of industry & $\mathrm{X}$ & & & $\mathrm{X}$ & & V & & & $\mathrm{X}$ & & & $\mathrm{X}$ & & $\mathrm{T}$ & & $\mathrm{X}$ \\
\hline If Vehicular related, & & & & & & & & & & & & & & & & \\
\hline Use of protective equip. & $\mathrm{X}$ & $\mathrm{TX}$ & $\mathrm{XR}$ & $\mathrm{X}$ & HT & $\mathrm{X}$ & & & $\mathrm{X}$ & & $\mathbf{X}$ & $\mathrm{X}$ & & & I & $\mathrm{X}$ \\
\hline Position in vehicle & $\mathrm{X}$ & $\mathrm{X}$ & & & & $\mathrm{V}$ & & & $\mathrm{X}$ & & & $\mathrm{X}$ & & & I & $\mathrm{X}$ \\
\hline Detail of vehicle & $\mathrm{X}$ & & & & & & & & & & & $\mathbf{X}$ & & & & \\
\hline Detail of crash & $\mathrm{X}$ & $\mathrm{T}$ & & & & & & & & & & $\mathrm{X}$ & & & I & \\
\hline Road conditions & $\mathrm{X}$ & & & $\mathrm{X}$ & & & & & & & & $\mathrm{X}$ & & & & \\
\hline Recreation related injury & $\mathrm{X}$ & & & $\mathrm{X}$ & $\mathrm{H}$ & & & & & & & $\mathrm{X}$ & & & I & \\
\hline Intentionality of injury & $\mathrm{X}$ & & & $\mathrm{X}$ & $\mathrm{T}$ & & & & $\mathrm{X}$ & & & $\mathrm{X}$ & & & RI & $\mathrm{X}$ \\
\hline Setting of injury (home, work, school) & & & & $\mathrm{X}$ & $\mathrm{T}$ & & & & & $\mathrm{X}$ & $\mathrm{X}$ & $\mathrm{X}$ & & $\mathrm{T}$ & I & \\
\hline
\end{tabular}


Table 2 (continued)

Emergency medical services (ems)

and hospital emergency

department treatment

Method of evacuation from injury site

Blood alcohol screen

Drug screen

Trip report \#

Time of ambulance run

Date/time of arrival ER

CT scan ER

Fluids given

Meds given

Time trauma surgeon,

Ortho-surgeon,

Neurosurgeon arrived ER

Time D/C from ER

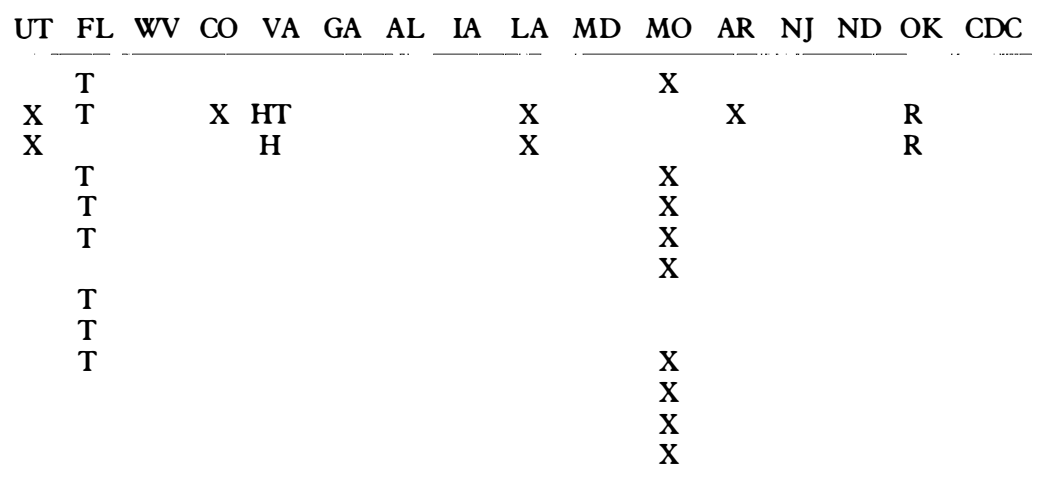

Associated injuries and

injury status

UT FL WV CO VA GA AL IA LA MD MO AR NJ ND OK CDC

Head injury suspected (SCI only)

Other significant injuries

Fractures

Glasgow coma score

Blood pressure

Respiration rate

Reporting source/hospital course

Registry ID number

Date of report

Name of person/hospital reporing

Phone number reporting source

Medical record number

Date of admission

Date of discharge

Transfer from/to

Method of transfer (ambulance, etc)

Attending physician

Speciality of attending

Phone number of attending

Type of treatment received

(MD, ER, hosp)

Cost of acute/rehab care

Length of stay acute/rehab

Total ICU days

Number of acute/rehab hosp treated at

Number of days away from usual activity

Complications during hospitalisation
UT FL WV CO VA GA AL IA LA MD MO AR NJ ND OK CDC

\begin{tabular}{|c|c|c|c|c|c|c|c|c|c|c|c|c|c|c|c|}
\hline $\mathrm{X}$ & $\mathrm{T}$ & & $\mathrm{X}$ & & & & & & & & $X$ & & & & $\bar{X}$ \\
\hline & $\mathrm{X}$ & XR & $\mathrm{X}$ & $\mathrm{X}$ & & & $\mathrm{X}$ & $\mathrm{X}$ & & & & $x$ & $\mathrm{~T}$ & II & \\
\hline $\mathrm{X}$ & $\mathrm{XT}$ & XR & $\mathrm{X}$ & $\mathrm{X}$ & $\mathrm{X}$ & $\mathrm{X}$ & $\mathrm{X}$ & $\mathrm{X}$ & $\mathrm{X}$ & & $\mathrm{X}$ & $\mathrm{X}$ & $\mathrm{T}$ & II & $\mathrm{X}$ \\
\hline & $\mathrm{X}$ & & & & $\mathrm{X}$ & & & $\mathrm{X}$ & & & & & & $\mathbf{P}$ & \\
\hline $\begin{array}{l}X \\
\mathbf{y}\end{array}$ & XT & & & HT & $\mathrm{X}$ & & & $\mathrm{X}$ & $\mathrm{X}$ & $\mathrm{X}$ & & & & $\mathrm{P}$ & \\
\hline & XT & & & $X 1$ & & & & & $\mathrm{X}$ & $\mathbf{X}$ & $\mathrm{X}$ & & & RI & \\
\hline$x$ & $\begin{array}{l}\mathrm{XT} \\
\mathrm{XT}\end{array}$ & & $\mathbf{X}$ & $\begin{array}{l}\text { HT } \\
\text { HT }\end{array}$ & $V$ & & & $\mathrm{X}$ & $\mathrm{x}$ & $\begin{array}{l}\mathrm{X} \\
\mathrm{x}\end{array}$ & $\mathrm{X}$ & $\mathrm{x}$ & & $\begin{array}{l}\text { RI } \\
\text { PI }\end{array}$ & $\mathrm{X}$ \\
\hline & $\mathrm{T}$ & & $\mathrm{X}$ & $\mathrm{T}$ & & & & & & & & & & & \\
\hline & & XR & $\mathrm{X}$ & $\mathrm{X}$ & & & & $\mathrm{X}$ & & & & $\mathrm{X}$ & $\mathrm{T}$ & & \\
\hline & & & & $\mathrm{X}$ & & & & $\mathrm{X}$ & & & & & & & \\
\hline & & & & $\mathrm{X}$ & & & $\mathrm{X}$ & & & & & & & $P$ & \\
\hline $\mathrm{X}$ & & & $\underset{\mathbf{y}}{\mathrm{X}}$ & UT & & & & & & & & & & & \\
\hline & $T$ & & & $T$ & & & & & & $\mathrm{X}$ & $\mathbf{A}$ & & 1 & & \\
\hline & & & $X$ & $\mathrm{H}$ & & & & & & & & & & & \\
\hline T & & & $\mathrm{H}$ & & & & & & & & & 1 & & & \\
\hline
\end{tabular}


Table 2 (continued)

\begin{tabular}{|c|c|c|c|c|c|c|c|c|c|c|c|c|c|c|c|c|}
\hline Resulting disability & UT & FL & WV & $\mathrm{CO}$ & VA & GA & $\mathrm{AL}$ & IA & LA & MD & MO & AR & NJ & ND & OK & $\mathrm{CDC}$ \\
\hline Spinal cord injury/disease & $\mathbf{X}$ & & & & & $\mathrm{X}$ & & & & & & $\mathbf{X}$ & & & & \\
\hline Level of injury & $\mathrm{X}$ & $\mathrm{X}$ & $\mathrm{XR}$ & $\mathrm{X}$ & XH & & $\mathrm{X}$ & $\mathrm{X}$ & $\mathbf{X}$ & & & $\mathbf{X}$ & $\mathrm{X}$ & $\mathrm{T}$ & PR & $\mathbf{X}$ \\
\hline Extend of injury & $\mathrm{X}$ & $\mathrm{X}$ & $\mathbf{R}$ & $\mathrm{X}$ & XH & & $\mathrm{X}$ & & $\mathbf{X}$ & & $\mathrm{X}$ & $\mathrm{X}$ & $\mathrm{X}$ & $\mathrm{T}$ & PR & $\mathrm{X}$ \\
\hline ICD-9-CM codes & $\mathbf{X}$ & $\mathrm{T}$ & & & XT & $\mathbf{X}$ & & $\mathbf{X}$ & & & $\mathbf{X}$ & & & $\mathrm{T}$ & & \\
\hline Type of urinary management & & & & $\mathrm{X}$ & $\mathrm{H}$ & & & & & & & & & & & \\
\hline Personal care attendent & & & & $\mathrm{X}$ & & & & & & & & & & & & \\
\hline Discharge disposition & $\mathrm{X}$ & $\mathrm{T}$ & $\mathrm{XR}$ & $\mathbf{X}$ & HT & V & & $\mathrm{X}$ & $\mathrm{X}$ & & $\mathrm{X}$ & $\mathrm{X}$ & & & $\mathbf{P}$ & $\mathrm{X}$ \\
\hline Degree of disability/code & $\mathrm{X}$ & & & $\mathrm{X}$ & & & & & & & $\mathrm{X}$ & $\mathbf{X}$ & & & & \\
\hline Date of death & $\mathrm{X}$ & $\mathrm{T}$ & & $\mathbf{X}$ & $\mathrm{XHT}$ & & $\mathbf{X}$ & & $\mathrm{X}$ & & & $\mathbf{X}$ & & & PR & \\
\hline Cause of death & & & & $\mathbf{X}$ & & & & & & & & $\mathbf{X}$ & & & & \\
\hline
\end{tabular}

Vocational rehabilitation

referral network

UT FL WV CO VA GA AL IA LA MD MO AR NJ ND OK CDC

Days to system notification

Days of case contact from system

DVR case/referral

Date of referral

Date case closed

Casework status

Case manager assigned

Patient referred/informed of services

Date patient contacted

Method of contact

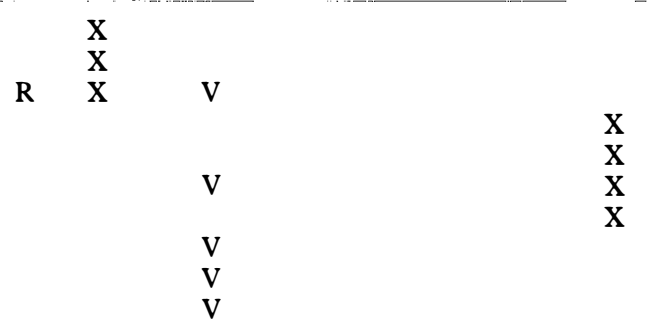

\begin{tabular}{ll}
\hline All States & Georgia \\
$\mathrm{X}=$ information collected for SCI registry. & $\begin{array}{l}\mathrm{X}=\text { initial registry report. } \\
\mathrm{V}=\text { information collected when patient is visited by a } \\
\text { rehabilitation counsellor. }\end{array}$ \\
$\begin{array}{l}\text { Florida } \\
\mathrm{X}=\text { initial SCI registry report. }\end{array}$ & $\begin{array}{l}\text { North Dakota } \\
\mathrm{T}=\text { information collected for trauma registry. }\end{array}$ \\
$\begin{array}{l}\mathrm{T}=\text { information collected for statewide trauma registry. } \\
\text { West Virginia }\end{array}$ & $\begin{array}{l}\text { Oklahoma } \\
\mathrm{X}=\text { initial registry report. }\end{array}$ \\
$\begin{array}{l}\mathrm{P}=\text { information collected by attending physician. } \\
\text { by a rehabilitation counsellor. }\end{array}$ & $\mathrm{R}=$ information collected during rehabilitation admission. \\
Virginia & $\mathrm{I}=$ information collected by patient interview. \\
$\mathrm{X}=$ initial registry report. & $\mathrm{CDC}$ \\
$\mathrm{H}=$ Data from the statewide hospital & $\mathrm{X}=$ working list of variables recommended by the Centers \\
data collection system. & for Disease Control SCI surveillance project as of February,
\end{tabular}

of injuries, where more detailed information on hospitalisation, outcome, etc. may be delayed depending on the length of time the patient is hospitalised.

\section{Information collected}

States vary considerably in terms of the data items collected. Table II contains a list of variables collected by each state. All states with registries collect basic descriptive information used to identify characteristics of the SCI individual (e.g., name, address, race, sex, birthdate/age), and information needed to describe the circumstances, treatment, and outcome of the injury (e.g., date and cause of injury, admission date and name of treating hospital, discharge disposition, level and extent of injury). 
Some states collect much more detailed information focusing on areas of interest to the administrating agency. For example, Florida, Virginia, and Missouri have several data items related to treatment provided by emergency medical services and the treating hospital's emergency department, information commonly found in trauma registries. Oklahoma, Colorado, Georgia, and Louisiana collect more detailed information on the circumstances of the injury (e.g., exact geographic location, alcohol/drug involvement, intentionality, use of seat belts if vehicular related, etc.) which can be used to target prevention activities.

The Centers for Disease Control, as part of its efforts toward required reporting of SCI on a national level, has distributed a list of suggested core variables to be included in SCI surveillance projects at the state level. The CDC's variables are also included in Table II.

\section{Usage of registry information}

Depending on the purpose of the registry, information collected is used for a variety of functions. Some states supply their reporting sources with qualitycontrol type of information to improve the quality and quantity of cases reported. Several states publish descriptive reports of registry data and supply information to those interested in health care planning, evaluation of health services, research, prevention, etc.

\section{Discussion}

In the United States, as well as many other developed countries, injuries are the leading cause of prematurely lost years of life, surpassing cancer and heart disease combined. Injury is a disease of the young, being the leading cause of death and disability in children and young adults. Public health surveillance of injuries such as SCI has recently begun to evolve, following years of experience with similar methods used for both infectious and chronic disease conditions.

The establishment of statewide SCI surveillance systems is an important first step in the battle against one of the United States' most preventable public health problems. While there are other sources of information on SCI incidence, aetiology, and treatment systems, these are based on unrepresentative population samples (e.g., the Database of the Model Systems), and/or do not focus exclusively on SCI cases, and as such omit much information crucial to the study of this type of injury (e.g., databases of Medicare and other sponsors of health care).

A statewide SCI surveillance system providing quality information may be used to focus injury intervention programs efficiently and also to evaluate the effectiveness of these programs. Information collected by a registry can give considerable insight into the nature of these types of injuries and provide a powerful tool to direct prevention efforts, health care planning, service provision and evaluation, and legislative efforts.

More and more state policy makers, administrators, advocacy and health care organisations are beginning to recognise the necessity of this type of information to target efforts toward reducing the impact of injuries in their own states. States with, or working towards the development of, such systems have the opportunity 
to establish a vital link toward the improvement of health and life span of residents and visitors.

It is unfortunate, however, that these separate initiatives have resulted in lack of comparability of the data resulting from the existing registries. Given the fact that in the United States the major responsibility for public health law, policy, funding, and organisation of health care systems lies with the states rather than the Federal Government, the wide variation in content, purpose, and methods of the existing SCI registries is not surprising.

The difficulty in establishing a uniform SCI registry on a national level is due not just to the existence of fifty states with responsibility for public health. The general organisation of health care in the United States also plays a role. There are approximately 7000 hospitals, with an estimated 840 rehabilitation hospitals and units, all of which compete for patients, whose care is being paid for by a mixture of public, semi-public, and private sources. In countries with nationalised or socialised medicine, or where a limited number of designated SCI centers are in existence, developing a surveillance system is rather simple-the major issue is one of deciding what type and quantity of information to include (e.g., compare the Australian experience where a single national registry is being set up (Wigglesworth, 1988)).

Since the publication of 'Injury in America' in 1985, the Centers for Disease Control have taken the lead in promoting the development of surveillance systems for sentinel injuries. Models have been published for the definition of SCI and for registry contents. Following the guidelines for SCI surveillance system development established by the CDC is an important step states can take toward collecting and analysing standardised information on these and other types of injuries on a national level.

Using the information available from states with previously established registries, and learning from their experience, will improve the quality and comprehensiveness of registry development. The 'ideal' system would follow the guidelines for the public health surveillance of SCI, established by the CDC, and then expand from that 'surveillance system' base to fulfill the additional 'registry' needs of the administrating agency and other interest groups within the state.

\section{Acknowledgements}

We wish to thank the following individuals for their critıque of this manuscript: Michael DeVivo, Alabama; Thomas Farley, Arkansas; Joseph Sniezek, Centers for Disease Control; Ken Gerhart, Colorado; Karen White, Florida; Sharon Short, Georgia; Gina Liggett, Louisiana; Rama Rameshrao, Maryland; Linda Ross, Bruce Gans and Patricia Waller, Michigan; Jay Thompson, Missouri; Tonnie Glick, New Jersey; Mark Kinde, North Dakota; Julian Hickman, Virginia.

\section{References}

Centers for Disease Control 1988a Guidelines for evaluating surveillance systems. Morbidity and Mortality Weekly Report 37(S-5): 1-18.

Centers for Disease Control 1988b Acute traumatic spinal cord injury surveillance-United States, 1987. Morbidity and Mortality Weekly Report 37(18):285--286.

GRAITCER PL 1987 The development of state and local injury surveillance systems. Fournal of Safety Research 18:191-198.

GUTTMANN L 1976 Spinal Cord Injuries. Blackwell Scientific, Oxford.

InJURy IN AmEriCA: A Continuing Public Health Problem 1985 Committee on Trauma Research, 
Commission on Life Sciences, National Research Council and the Institute of Medicine, National Academy Press, Washington, D.C.

InJURy Prevention: Meeting The Challenge 1989 The National Committee for Injury Prevention and Control, Oxford University Press: New York (printed as a supplement to the Americanfournal of Preventive Medicine (1989), 5(3).

International Classification of Diseases 9th Revision, Clinical Modification (second printing, 1980). Publisher: Commission on Professional and Hospital Activities: Ann Arbor, Michigan.

KRAUS JF 1985 Epidemiological aspects of acute spinal cord injury: A review of incidence, prevalence, causes and outcome. In Becker DP \& Povlishock JT (eds.) Central Nervous System Trauma Status Report. Bethesda, Maryland: National Institute of Neurological and Communicative Disorders and Stroke, National Institute of Health, pp. 313-322.

National CENTER fOR Health STATISTICS. Advanced report of final mortality statistics, 1985. Washington, D.C.: U.S. Government Printing Office, 1987.

National Center for Health Statistics. Current estimates from the National Health Interview Survey, United States, 1985. Washington, D.C.: U.S. Government Printing Office, 1986.

Proposed Case Definition and Variable Description. Spinal Cord Injury Surveillance Project, Centers for Disease Control. February, 1989.

Stover SL, Fine PR eds. 1986 Spinal Cord Injury: The Facts \& Figures. University of Alabama, Birmingham: 1-9.

ThaCKer SB, Berkelman RL 1988 Public health surveillance in the United States. Epidemiologic Reviews, 10:164-190.

Promoting Health/Preventing Disease: Year 2000 Objectives for the Nation (Draft for Public Review and Comment). United States Department of Health and Human Services, Public Health Service (September, 1989).

WIGGLESWORTH EC 1988 Toward prevention of spinal cord injury: The role of a national register. Paraplegia 26:389-392. 